Full length article

\title{
Unveiling the fate of adhering bacteria to antimicrobial surfaces: expression of resistance-associated genes and macrophage-mediated phagocytosis
}

\author{
Diana F. Alves ${ }^{\mathrm{a}, *}$, Andreia P. Magalhães ${ }^{\mathrm{a}}$, Damian Neubauer ${ }^{\mathrm{b}}$, Marta Bauer ${ }^{\mathrm{b}}$, Wojciech Kamysz ${ }^{\mathrm{b}}$, \\ Maria O. Pereira ${ }^{\text {a }}$ \\ ${ }^{a}$ CEB - Centre of Biological Engineering, LIBRO - Laboratório de Investigação em Biofilmes Rosário Oliveira, University of Minho, Campus de Gualtar, 4710-057 Braga, Portugal \\ ${ }^{\mathrm{b}}$ Faculty of Pharmacy, Medical University of Gdansk, 80-416 Gdansk, Poland
}

\section{A R T I C L E I N F O}

\section{Article history:}

Received 29 March 2018

Received in revised form 16 July 2018

Accepted 29 July 2018

Available online 31 July 2018

\section{Keywords:}

Microbial resistance

Antimicrobial coatings

Macrophages

Biomaterial-associated infections

\begin{abstract}
A B S T R A C T
Since most antibacterial coatings reported to fight biomaterial-associated infections (BAI) fail in completely preventing bacterial colonization, it is crucial to know the impact of that small fraction of adhered bacteria in BAI recrudescence. This study aims to understand the fate of Staphylococcus aureus able to adhere to an antimicrobial coating previously developed, in terms of potential development of bacterial resistance and their macrophage-mediated phagocytosis. Antimicrobial coating comprised the coimmobilization of Palm peptide and DNase I onto polydimethylsiloxane. Expression of genes associated to resistance and virulence mechanisms showed that cells in contact with antimicrobial surfaces for a long period of 30 days, exhibit genes equally or less expressed, as compared to cells recovered from control surfaces. Recovered cells also exhibit the same susceptibility patterns, which strengthens the evidence of no resistance development. Remarkably, cells adhered to modified surfaces shows a reduced metabolic activity upon vancomycin treatment unlike the cells found on control surfaces, which can be identified as a clinical opportunity for prophylactically administration after implant surgery. Furthermore, results highlight that functionalization of PDMS with Palm and DNase I should not compromise the action of host immune cells. The overall results reinforce the potential of this antimicrobial strategy to fight BAI.
\end{abstract}

๔) 2018 Acta Materialia Inc. Published by Elsevier Ltd. All rights reserved.

\section{Introduction}

Polydimethylsiloxane (PDMS), commonly referred as silicone rubber, is used for a wide variety of biomedical applications due to its excellent biocompatibility and mechanical properties. For instance, it has been used in vascular grafts [1], catheters [2], stents [3], breast implants [4] and voice prostheses [5]. However, PDMSbased biomedical devices are prone to microbial adhesion which can be a prelude for biofilm formation and infection. Biofilmassociated infections are extremely difficult to eradicate because cells within a biofilm encase themselves in a self-produced matrix which confers them protection against antimicrobial treatment and host immune system [6,7]. Very often, the only solution for an infected implant relies on its surgical removal at the expenses of considerable costs and patient suffering. Moreover, the removal of the infected implant may not completely solve the problem due

\footnotetext{
* Corresponding author.

E-mail address: dianalves@ceb.uminho.pt (D.F. Alves).
}

to the pathogen burden remaining in the body which is responsible for recurrent infection [8].

Several strategies to modify PDMS surface have been reported to prevent bacterial colonisation. For example, silicone catheters have been impregnated with antibiotics such as minocycline/ rifampin [9], triclosan [10] and nitrofuzane [11]. Although this approach proved to prevent bacterial adhesion and biofilm formation on these surface-coated catheters, there are some drawbacks that limit their clinical application, mainly their short-term antibacterial effect and the potential development of bacterial resistance [12]. An alternative approach relies on the use of silver or silver nanoparticles to coat the surfaces of catheters, but its potential has been compromised by the high cost of the silver coatings and the conflicting clinical results regarding silver safety [13]. Covalent immobilization of antimicrobials offers an alternative approach that avoids patient exposure to leaching compounds and potentially increases the duration of antimicrobial efficacy [14]. This strategy should be employed with antimicrobial agents working at the level of the cell wall or membrane, since they can 
only reach the outside of the microbial cells. Quaternary ammonium silane, antimicrobial peptides (AMP) and enzymes targeting the components of biofilms matrix are examples of commonly used antimicrobial agents that have been covalently immobilized onto PDMS surfaces to prevent BAI [14-16]. Although the results obtained with these strategies have been encouraging, there are some challenges in the field of antibacterial coatings that urgently need to be solved so they can be applied in clinical practice.

An important issue is associated to the fact that most of the coatings reported in the literature are not able to completely prevent bacterial adhesion. Therefore, it is crucial to determine if the "few" bacteria that manage to adhere to these coatings are able to grow into a mature biofilm. For instance, Nejadnik et al. have demonstrated the ability of few bacteria that adhered on a polymer brush-coating to form a weakly adhering biofilm [17]. Another challenge is the potential development of microbial resistance towards the antimicrobials released from the surfaces. Although antimicrobials permanent immobilization has been proposed as an alternative approach to minimize antimicrobial resistance development, because covalent immobilization avoids exposure to sub-inhibitory concentrations $[18,19]$, there is a lack of studies addressing these issues.

Another crucial factor influencing the pathogenesis of BAI, often neglected in the field of antibacterial coatings, is the role of host's immune system. Once a BAI is established, different immune cells are recruited to the infection site but macrophages end up being the prevailing cells responsible to orchestrate the inflammatory process and foreign body reactions [20,21]. Their functions include ingestion of bacteria by phagocytosis, destruction of bacteria within the phagolysosome and recruitment of inflammatory cells to the site of infection, using chemokines and acute-phase proteins. It has been reported, however, that the presence of a biomaterial may compromise the host immune system [22]. Therefore, it is important to better understand how immune cells interact with adhering pathogens.

In our previous work, the antimicrobial peptide Palm and the enzyme DNase I were successfully co-immobilized onto PDMS surfaces to impart them with both anti-adhesive and antimicrobial properties against the adhesion of relevant bacteria as single and dual-species, with excellent stability and non-toxicity [23]. Although the results obtained were quite promising, it cannot be neglected the fact that some bacteria managed to adhere to these coatings. So, as a follow-up of this previous work, the goal of the present study was to provide some insights about the potential development of resistance by bacteria remaining on these functionalized PDMS surfaces towards the antimicrobials immobilized. It was also intended to investigate the role of these bi-functional coatings on PDMS-adherent bacteria removal and digestion by macrophages.

\section{Materials and methods}

\subsection{Bacterial strain and growth conditions}

Staphylococcus aureus GB 2/1 isolated from explanted voice prostheses at the University Medical Centre of Groningen (the Netherlands) was used throughout this study. The strain was first streaked on a tryptic soy agar (TSA, Liofilchem) plate from a frozen stock solution and grown for $24 \mathrm{~h}$ at $37^{\circ} \mathrm{C}$. For each experiment, a few colonies were collected from the TSA plates and grown overnight in batches of tryptic soy broth (TSB, Liofilchem) at $37^{\circ} \mathrm{C}$ under agitation $(120 \mathrm{rpm})$. Subsequently, cells were harvested by centrifugation ( $9000 \mathrm{~g}, 5 \mathrm{~min}$ ) and washed in sterile saline solution $(0.9 \% \mathrm{NaCl}$ prepared in ultrapure water). The concentration of cellular suspensions was adjusted by optical density at $640 \mathrm{~nm}$ and calibrated in terms of Colony Forming Units (CFU) using the spread plate method.

\subsection{AMP, enzyme and antibiotic}

The enzyme DNase I and the antibiotic vancomycin were purchased by AppliChem (Germany) and the AMP Palm-KGK-NH ${ }_{2}$ (Palm) was synthesized manually by solid-phase synthesis method on polystyrene AM-RAM resin, using Fmoc/tButyl strategy as previously described [24]. Coupling was performed with HOBt/DIPCDI method, the Fmoc protecting group were removed with 20\% piperidine. Crude peptides were cleaved from resin using a mixture of trifluoroacetic acid (TFA), triisopropylsilane (TIS) and water as scavengers. The final products were purified by reverse-phase high performance liquid chromatography (RP-HPLC) in a mixture of acetonitrile - water with $0.1 \%$ TFA as an eluent. Molecular weights of peptides were determined by matrix - assisted laser desorption ionization-time of flight mass spectrometry (MALDI-TOF).

\subsection{Determination of minimal inhibitory and bactericidal concentrations}

The minimal inhibitory (MIC) and bactericidal (MBC) concentrations of antimicrobials against $S$. aureus GB 2/1 were determined by the microdilution method according to Clinical and Laboratory Standards Institute (formerly NCCLS) [25]. Briefly, the wells of a sterile 96-well round-bottom microtiter plates (polystyrene, Orange, USA) were filled with $100 \mu \mathrm{L}$ of MHB (Mueller-Hinton broth) with increasing concentrations of antimicrobial to which were added $100 \mu \mathrm{L}$ of each bacterium inoculums (adjusted to a final concentration of $5.0 \times 10^{5} \mathrm{CFU} \cdot \mathrm{mL}^{-1}$ ). The plates were afterwards incubated at $37{ }^{\circ} \mathrm{C}$ for $24 \mathrm{~h}$ in an orbital shaker at 120 rpm. In this assay, two controls were used, one without bacteria as a negative control and one without antimicrobials as a positive control. Moreover, culture media with increasing concentrations of antimicrobials without bacteria were also performed in order to avoid misleading results. The MIC was obtained by measuring the absorbance at $640 \mathrm{~nm}\left(A_{640 \mathrm{~nm}}\right)$, where clear wells $\left(A_{640 \mathrm{~nm}}=\right.$ negative control) were evidence of bacterial growth inhibition. MBC determination was performed by adding a droplet of $10 \mu \mathrm{L}$ from each well with no visible growth on a TSA plate. The lowest concentration that yielded no colony growth after $24 \mathrm{~h}$ at $37^{\circ} \mathrm{C}$ was identified as the MBC.

\subsection{PDMS preparation and further functionalization}

PDMS (kit Sylgard 184, Dow Corning, USA) was prepared and functionalized with the lipopeptide Palm and enzyme DNase I as previously described [23]. Briefly, the first step involved the deposition of a polydopamine (pDA) coating onto PDMS coupons which was performed by immersing them in $7 \mathrm{~mL}$ of a freshly prepared solution of dopamine (Sigma, $2 \mathrm{mg} \cdot \mathrm{mL}^{-1}$ dopamine-HCl in 10 $\mathrm{mM}$ bicine buffer, $\mathrm{pH} 8.5$, Sigma) for $18 \mathrm{~h}$ at room temperature (RT) and under agitation (70 rpm). Surfaces were then rinsed with ultrapure water. For further functionalization, pDA-coated coupons were immersed in a mixture solution composed of DNase I (1 $\mathrm{mg} \cdot \mathrm{mL}^{-1}$ in $150 \mathrm{mM} \mathrm{NaCl}, 10 \mathrm{mM}$ potassium phosphate buffer supplemented with $10 \mathrm{mM} \mathrm{MgCl}_{2}, \mathrm{pH}$ 6.8) and Palm (1 mg. $\mathrm{mL}^{-1}$ in PBS, pH 7.4) in a proportion of $1: 3$, respectively (MIX), and were incubated for $6 \mathrm{~h}$, at RT, under agitation (70 rpm).

\subsection{Planktonic cultures exposure to a sub-lethal concentration of antimicrobials}

The potential development of resistance was first evaluated for planktonic cells with antimicrobials in solution, following a proce- 
dure previously described by Cooper et al. [26]. Besides Palm, the antimicrobial lipopeptide used to functionalize PDMS surfaces together with the enzyme DNase I, a traditional antibiotic, often used in clinical practice to fight BAI, vancomycin, was also investigated in these tests for comparison purposes. Briefly, $40 \mu \mathrm{L}$ of an overnight culture of $S$. aureus GB 2/1 was inoculated in $20 \mathrm{~mL}$ of TSB medium containing a sub-inhibitory concentration of Palm $\left(8 \mu \mathrm{g} \cdot \mathrm{mL}^{-1}\right)$ or vancomycin $\left(0.125 \mu \mathrm{g} \cdot \mathrm{mL}^{-1}\right)$. The flask was then incubated at $37^{\circ} \mathrm{C}$ and $120 \mathrm{rpm}$ for $24 \mathrm{~h}$. For 10 successive days, similar and freshly prepared flasks were inoculated with $40 \mu \mathrm{L}$ of preceding days' culture. The MIC and MBC of Palm and vancomycin were determined, as previously described, on days 0 and 10 . Two independent assays were performed.

\subsection{Evaluation of modified surfaces potential to induce bacterial resistance}

To evaluate the potential development of resistance of cells adhered to the immobilized agents, a similar procedure to evaluate the potential development of resistance in planktonic cultures was performed, in which cells adhered to the surfaces with and without modification were collected and placed in contact with new surfaces for 30 days. For comparison purposes, the antibiotic vancomycin was immobilized onto PDMS using dopamine chemistry (details of this immobilization can be found in Supplemental Material, Figs. S1 and S2). Briefly, a bacterial suspension with $1 \times 10^{7}$ $\mathrm{CFU} \cdot \mathrm{mL}^{-1}$ was prepared in TSB and $300 \mu \mathrm{L}$ of this suspension were added to a 48-well microtiter plate in which PDMS, pDA, and pDA further functionalized with Palm and DNase I (MIX) or vancomycin (VANC) were placed. The plate was incubated for $3-4$ days at $37^{\circ} \mathrm{C}$ and $120 \mathrm{rpm}$, with TSB replacement every 1.5-2 days. The coupons were subsequently washed with saline solution to remove freefloating bacteria and transferred to an Eppendorf tube with $1 \mathrm{~mL}$ of saline solution. The tubes were then sonicated for $6 \mathrm{~min}$, subjected to vortex for $30 \mathrm{~s}$ (these parameters were previously optimized) and $300 \mu \mathrm{L}$ of this suspension were added to a 48 -well microtiter plate in which new silicone coupons were placed. The procedure was repeated for 30 successive days. The MIC and $\mathrm{MBC}$ for each condition tested were determined after this period and compared. Moreover, the transcript levels of some genes involved in antimicrobial resistance and virulence mechanisms were assessed using quantitative real time PCR (qRT-PCR). This analysis was carried out for cells recovered from the different surfaces tested, being afterwards grown in solid media before RNA extraction. Cells recovered from the control surfaces (PDMS and pDA) were grown in TSA whereas cells retrieved from the surfaces functionalized, PALM or VANC were grown in TSA supplemented with a sub-inhibitory concentration of Palm and vancomycin, respectively, to keep the stress conditions. The colonies recovered from two replicated surfaces were pooled together in RNase free water in order to reduce the variability associated with gene expression quantification from biofilm samples [27], and centrifuged to pellet before RNA extraction. Three independent experiments in duplicate were performed.

Supplementary data associated with this article can be found, in the online version, at https://doi.org/10.1016/j.actbio.2018.07.052.

\subsection{Gene expression analysis}

\subsubsection{RNA extraction}

RNA was extracted using the RNeasy mini kit (Qiagen) as previously optimized [28], with some modifications. Briefly, bacterial pellets were suspended in $500 \mu \mathrm{L}$ of Lysis buffer RLT (provided by the kit) and $500 \mu \mathrm{L}$ of phenol solution (AppliChem, Darmstadt) and transferred to a $2 \mathrm{~mL}$ safe lock tube containing $0.4 \mathrm{~g}$ of acid-washed 150-212 mm silica beads (Sigma). This mixture was vortexed before using the FastPrepH cell disruptor (BIO 101, Thermo Electron Corporation, Thermo Scientific) with the following settings: $6.5 \mathrm{~m} \mathrm{~s}^{-1}$ for $35 \mathrm{~s}$. Samples were, afterwards, transferred to a new tube and mixed with equal volume of $70 \%$ ethanol (Fisher Scientific). Finally, RNA elution was achieved by adding $50 \mu \mathrm{L}$ of RNase-free water to the centre of the membrane. Following extraction, RNA was treated with DNase I (Thermo Scientific) to digest possible contaminating genomic DNA, as previously described [28]. Briefly, $2 \mu \mathrm{L}$ of DNase I and $5 \mu \mathrm{L}$ of reaction buffer were added to the RNA sample and incubated at $37{ }^{\circ} \mathrm{C}$ for $30 \mathrm{~min}$. Then, to inactivate the DNase I enzyme, $5 \mu \mathrm{L}$ of $25 \mathrm{mM}$ EDTA was added to the mixture and incubated at $65^{\circ} \mathrm{C}$ for $10 \mathrm{~min}$.

\subsubsection{RNA quality determination}

RNA samples concentration and purity were spectrophotometrically determined using a NanoDrop 1000TM (Thermo Scientific). The absorbance ratio A260/A280 was used as an indicator of protein contamination and A260/A230 as an indicator of polysaccharide, phenol, and/or chaotropic salt contamination [29]. Gel electrophoresis was used to assess the integrity of RNA samples through visualization of the $23 \mathrm{~S} / 16 \mathrm{~S}$ banding pattern. Electrophoresis was carried out at $80 \mathrm{~V}$ for $60 \mathrm{~min}$ using a $1.5 \%$ agarose gel. The gel was stained with GelRed and visualized using a GelDoc2000 (Bio-Rad, Hercules, CA, US). RNA was stored at $-80^{\circ} \mathrm{C}$ for further use.

\subsubsection{Gene expression quantification}

For the quantification of gene expression by qPCR, total RNA was reverse transcribed to complementary DNA (cDNA) using GRS cDNA Synthesis Kit (Grisp) following the manufacturer's instructions. The same amount of total RNA (300 ng) was reverse transcribed in $10 \mu \mathrm{L}$ of reaction volume. The samples were incubated at $65^{\circ} \mathrm{C}$ for $5 \mathrm{~min}$, $37^{\circ} \mathrm{C}$ for $60 \mathrm{~min}$, and $70^{\circ} \mathrm{C}$ for $10 \mathrm{~min}$. Random primers for the amplification of 16S rRNA, a housekeeping gene, and specific virulence genes (Table 1) were designed using the Primer3 software [30], having as templates the genomes with the following accession number: CP009361.1. The qPCR reaction was prepared by mixing together $5 \mu \mathrm{L}$ of master MIX SYBR Xpert Fast SYBR (Grisp), $2 \mu \mathrm{L}$ of $1: 100$ diluted cDNA, $0.5 \mu \mathrm{L}$ of $5 \mu \mathrm{M}$ forward and reverse primes and water up to $10 \mu \mathrm{L}$. The efficiency of primers was determined by the dilution method [31,32]. Quantitative RT-PCR run was performed on a CFX 96 (Bio-Rad) with the following cycle parameters: $95^{\circ} \mathrm{C}$ for $3 \mathrm{~min}, 40$ cycles of $95^{\circ} \mathrm{C}$ for $5 \mathrm{~s}$ and $60^{\circ} \mathrm{C}$ for $20 \mathrm{~s}$. Quantitative PCR products were analysed by melting curves for unspecific products or primer dimer formation. Relative fold increase of specific mRNA transcripts, was determined by applying the Pfaffl equation [33] using 16S rRNA as reference gene. Data analysis was based on three independent experiments.

\subsection{Cells susceptibility to vancomycin chemotherapy}

Cells susceptibility to vancomycin chemotherapy was evaluated by determining their metabolic activity, using the XTT reduction assay. Briefly, a bacterial suspension with $1 \times 10^{7} \mathrm{CFU} \cdot \mathrm{mL}^{-1}$ was prepared in TSB and $300 \mu \mathrm{L}$ of this suspension were added to a 48-well microtiter plate in which coupons of unmodified PDMS, pDA-coated PDMS (pDA) and pDA further functionalized with DNase I and Palm (MIX) were placed. The plate was incubated for $24 \mathrm{~h}$ at $37^{\circ} \mathrm{C}$, under agitation $(120 \mathrm{rpm})$. The coupons were subsequently washed once with saline solution to remove freefloating bacteria and $300 \mu \mathrm{L}$ of vancomycin (MIC prepared in TSB) was added to each well. As a control, $300 \mu \mathrm{L}$ of TSB without antibiotic was also added. The plates were then incubated overnight at $37^{\circ} \mathrm{C}$ and $120 \mathrm{rpm}$, and metabolic activity was determined using XTT reduction assay as previously described [34], with some modifications. This method is based on the reduction of XTT by 
Table 1

Oligonucleotide sequences of the primers used for gene expression quantification by qPCR

\begin{tabular}{|c|c|c|c|c|c|}
\hline Target gene & Direction & Sequence $\left(5^{\prime} \rightarrow 3^{\prime}\right)$ & Melting Temperature $\left({ }^{\circ} \mathrm{C}\right)$ & Amplicon size (bp) & Priming efficiency (\%) \\
\hline \multirow[t]{2}{*}{$16 S$ rRNA } & $\mathrm{F}$ & GGTCTTGCTGTCACTTATAGATGG & 59.2 & 164 & 90.4 \\
\hline & $\mathrm{R}$ & CGGAAGATTCCCTACTGCTG & 59.8 & & \\
\hline \multirow[t]{2}{*}{ walKR } & $\mathrm{F}$ & TTGTCCGAAGATGAAGCAAG & 59.0 & 248 & 93.7 \\
\hline & $\mathrm{R}$ & CGCAGTAACGAACGACGATA & 59.9 & & \\
\hline \multirow[t]{2}{*}{$\operatorname{vraSR}$} & $\mathrm{F}$ & CCGGCAATATAACCTGCACT & 60.0 & 220 & 111.7 \\
\hline & $\mathrm{R}$ & GTAGTTGCGACGGATGAGGT & 60.0 & & \\
\hline \multirow[t]{2}{*}{ mdeA } & $\mathrm{F}$ & GCGAGAGGTGAAACGTTAGC & 60.0 & 256 & 94.1 \\
\hline & $\mathrm{R}$ & AGAACAGAGCAGCAGCAACA & 60.0 & & \\
\hline \multirow[t]{2}{*}{ norA } & $\mathrm{F}$ & ССАССТGСТССТАСТАСАААСА & 59.0 & 212 & 99.1 \\
\hline & $\mathrm{R}$ & ATGGAAAAGCCGTCAAGAGA & 60.0 & & \\
\hline \multirow[t]{2}{*}{ hla } & $\mathrm{F}$ & ACCGCCAATTTTTCCAGAAT & 60.7 & 167 & 98.6 \\
\hline & $\mathrm{R}$ & CCTGGCCTTCAGCATTTAAG & 60.8 & & \\
\hline \multirow[t]{2}{*}{ clpP } & $\mathrm{F}$ & AACAACAAATCGCGGTGAAC & 60.9 & 265 & 91.2 \\
\hline & $\mathrm{R}$ & TGCAGCCATACCGATACAAA & 60.1 & & \\
\hline \multirow[t]{2}{*}{$r p o B$} & $\mathrm{~F}$ & AGTTCGTTCACCATCCGTTT & 59.5 & 275 & 100.6 \\
\hline & $\mathrm{R}$ & CAGTGTTTTCAGTGCCGTCT & 59.0 & & \\
\hline
\end{tabular}

F, forward. R, reverse.

metabolically active cells to a water-soluble orange formazan. The produced formazan can be quantified by spectrophotometry analysis, being therefore proportional to the bacterial metabolic activity [35]. After biofilm growth and washing procedures as aforementioned, $400 \mu \mathrm{L}$ of a combined solution of XTT and phenazine methosulfate (PMS, Sigma) were added to each well in order to obtain a final concentration of $150 \mu \mathrm{g} \cdot \mathrm{mL}^{-1}$ of XTT and 10 $\mu \mathrm{g} \cdot \mathrm{mL}^{-1}$ of PMS. The plates were afterwards incubated at $37^{\circ} \mathrm{C}$ for $3 \mathrm{~h}$, at $120 \mathrm{rpm}$, in the dark. The absorbance of each well was then measured at $490 \mathrm{~nm}$ using a microtiter plate reader. Two independent assays with three replicates for each condition tested were performed.

\subsection{Macrophages adhesion to staphylococci adhering to surfaces}

Prior to macrophages adhesion, staphylococci were allowed to adhere to un- and modified surfaces. A bacterial suspension with $1 \times 10^{8} \mathrm{CFU} \cdot \mathrm{mL}^{-1}$ was prepared in PBS from an overnight culture at $37{ }^{\circ} \mathrm{C}$. PDMS coupons were then placed into the wells of a 48 well tissue culture plate (Orange Scientific, USA) and covered with $300 \mu \mathrm{L}$ of bacterial suspension. The samples were kept at $37^{\circ} \mathrm{C}$ and $120 \mathrm{rpm}$ for $4 \mathrm{~h}$. A human monocyte line cell (THP-1, ATCC TIB202) was used in this study. Monocytes were routinely cultured in (RPMI-1640) with sodium bicarbonate and L-glutamine, supplemented with $10 \%$ FBS and $1 \%$ penicillin/streptomycin. The flasks were kept at $37{ }^{\circ} \mathrm{C}$ in a humidified atmosphere with $5 \% \mathrm{CO}_{2}$ and cells were passaged when reached the exponential phase of growth (3-8 $\times 100000$ cells $\left.\cdot \mathrm{mL}^{-1}\right)$. Cells were harvested by centrifugation ( 5 min at $150 \mathrm{~g}$ ) and the harvested cells were counted using a Burker-Turk hemocytometer. To induce monocytes differentiation into macrophages, $1 \times 10^{6}$ cells $\cdot \mathrm{mL}^{-1}$ were diluted in RPMI supplemented with $100 \mathrm{nM}$ of phorbol 12-Myristate 13 (PMA) and cultured for $24 \mathrm{~h}$ at $37{ }^{\circ} \mathrm{C}$ and $5 \% \mathrm{CO}_{2}$. Cells in suspension were afterwards removed by aseptically removing the medium and adhered cells were washed with RPMI and incubated for more $48 \mathrm{~h}$ in medium without PMA. Cells were detached using trypsin and $300 \mu \mathrm{L}$ of a cell suspension with $5 \times 10^{5}$ cells $\cdot \mathrm{mL}^{-1}$ were added to each well of a 48-well microtiter plate in which the modified surfaces with staphylococci adhered as aforementioned were previously inserted. The plates were incubated at $37^{\circ} \mathrm{C}, 5 \% \mathrm{CO}_{2}$ for $2 \mathrm{~h}$. As a control, modified surfaces with adhered staphylococci were exposed to RPMI without macrophages. The coupons were washed with PBS, stained with DAPI $\left(40 \mu \mathrm{g} \cdot \mathrm{mL}^{-1}\right)$ and were visualized under an epifluorescence microscope (Leica, DMI 3000B). An indirect evaluation of bacteria phagocytosis was performed (details of this analysis can be found in Supplemental Material, Fig. S3).

\subsection{Statistical analysis}

Results were presented as mean \pm standard deviation (SD). Statistical analysis was performed using Graph Pad Prism 7.0. To compare gene expression levels, one-way ANOVA followed by Tukey's test was implemented. Metabolic activity of adhered cells with and without vancomycin treatment was determined using a Two-way ANOVA followed by Bonferroni's test. In all the analysis performed, the confidence interval used was $95 \%$.

\section{Results}

\subsection{Potential development of resistance by planktonic cultures towards Palm or vancomycin}

The potential of Palm and vancomycin to induce microbial resistance was first investigated when in solution against planktonic cultures of $S$. aureus (Table 2). Results showed a 2-fold increase in MIC and MBC of Palm and in the MIC of vancomycin after 10 days of exposure, indicating that planktonic cultures of $S$. aureus have become less susceptible to both antimicrobials. However, no changes on MBC of vancomycin were observed.

\subsection{Expression of genes associated to antimicrobial resistance and virulence mechanisms}

Quantitative RT-PCR analysis was implemented to deeply investigate whether the antimicrobials used to functionalize PDMS surfaces could exert any effect on the expression of genes associated to antimicrobial resistance and virulence mechanisms. For this analysis, 16s rRNA was used for normalization, and the outcomes were formulated as fold-change levels relative to the colonies of planktonic cultures (Fig. 1) and to the colonies of the cells recovered from unmodified surfaces of PDMS (Fig. 2). The expression level of two vancomycin resistance-associated genes, namely,

Table 2

Antimicrobial susceptibility of planktonic cultures of $S$. aureus GB 2/1 against Palm and vancomycin: MIC and MBC on day 0 and after 10 passages in a sub-inhibitory concentration. MIC and MBC are expressed in $\mu \mathrm{g} / \mathrm{mL}$.

\begin{tabular}{llllll}
\hline Antimicrobial & Day 0 & & & Day 10 & \\
\cline { 2 - 3 } \cline { 5 - 6 } & MIC & MBC & & MIC & MBC \\
\hline Palm & 64 & 64 & & 128 & 128 \\
Vancomycin & 1 & 2 & 2 & 2 \\
\hline
\end{tabular}




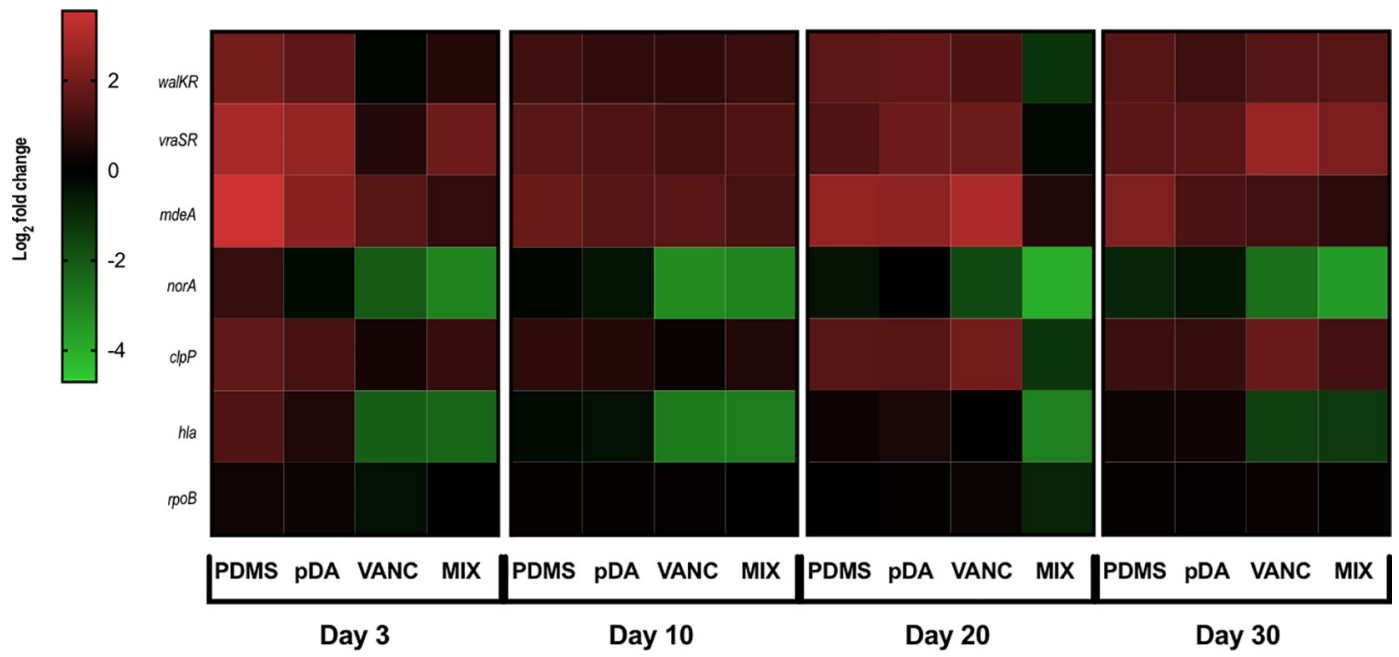

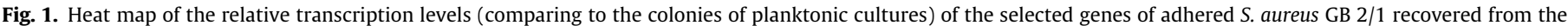

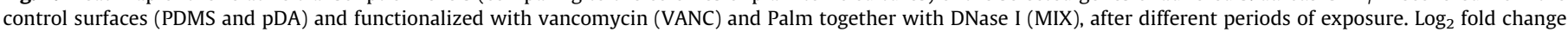

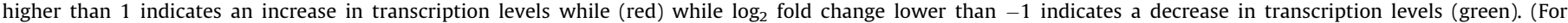
interpretation of the references to colour in this figure legend, the reader is referred to the web version of this article.)

vraSR and walKR, already upregulated in the cells recovered from the control surfaces (PDMS and pDA), were also upregulated in the cells exposed to the functionalized surfaces and an increase along time was observed, especially for the vraSR gene. Overexpression of these genes, in general, may be attributed to the

\section{$\log _{2}$ fold change}
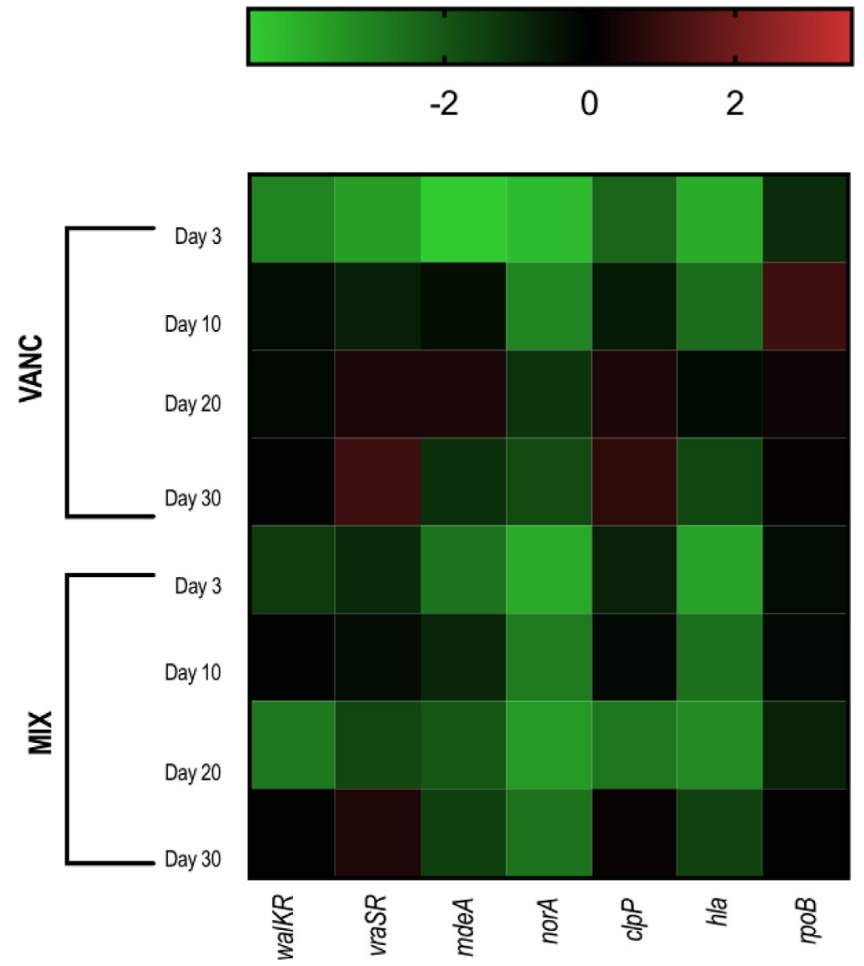

Fig. 2. Heat map of the relative transcription levels (comparing to the colonies of cells recovered from PDMS surfaces on each period) of the selected genes of adhered $S$. aureus GB $2 / 1$ recovered from the surfaces functionalized with vancomycin (VANC) and Palm together with DNase I (MIX), after different periods of exposure. $\log _{2}$ fold change higher than 1 indicates an increase in transcription levels while (red) while $\log _{2}$ fold change lower than -1 indicates a decrease in transcription levels (green). (For interpretation of the references to colour in this figure legend, the reader is referred to the web version of this article.) transition from planktonic to an adherent state, which leads to changes in gene expression [36]. Results showed no differences on the expression level of $r p o B$ on cells recovered from the control surfaces when compared to the planktonic cultures and a similar expression was found for cells recovered from both functionalized surfaces. Furthermore, the expression of this gene was not influenced by the exposure time.

The two genes investigated, encoding two different efflux pumps, presented different expression profiles. mdeA gene, already upregulated in the cells recovered from the control surfaces, was also upregulated in the cells recovered from both functionalized surfaces (VANC and MIX). Over time, a slight decrease on the transcription of this gene was found, especially for the cells in contact with MIX. Regarding norA gene, the transition of planktonic to an adhered state had no effect on its transcription for the control surfaces. On the other hand, the expression levels of this gene were greatly decreased for cells recovered from both functionalized surfaces. This downregulation, compared to the control surfaces $(p<$ 0.05 ), was observed from the beginning until the end of the 30 days of exposure, especially noticed, in the end, for the cells recovered from MIX.

It was found no differences on the expression level of hla on cells recovered from the control surfaces, when compared to the planktonic cultures. On the other hand, both functionalized surfaces (VANC and MIX) should suppress alpha hemolysin production by downregulating the expression of hla $(\mathrm{P}<0.05)$ and this downregulation was kept over time. Regarding the expression of clpP, this one was found increased for the cells recovered from the control surfaces (PDMS and pDA) over time, and a similar transcription was found for the functionalized surfaces during the first 10 days of exposure. In the last days, however, an increase on the expression levels of this gene for the cells in contact with VANC was observed (Fig. 2).

\subsection{Susceptibility patterns of cells recovered from surfaces}

Cells in contact with unmodified and modified PDMS surfaces were recovered after 30 days and used to determine the MIC and MBC of Palm and vancomycin (Table 3). It was possible to conclude that cells adhered to MIX exhibited the same susceptibility patterns of cells permanently exposed to unmodified surfaces (PDMS and pDA), suggesting no development of resistance. When it comes 
Table 3

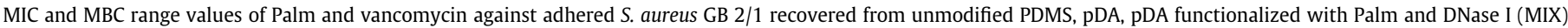

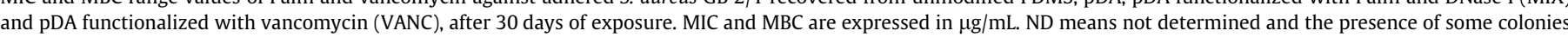
found for some concentrations are denoted in brackets.

\begin{tabular}{|c|c|c|c|c|c|c|c|c|}
\hline \multirow[t]{2}{*}{ Antimicrobial } & \multicolumn{4}{|l|}{ MIC } & \multicolumn{4}{|l|}{$\mathrm{MBC}$} \\
\hline & PDMS & pDA & MIX & VANC & PDMS & pDA & MIX & VANC \\
\hline Palm & $32-128$ & $32-128$ & $32-128$ & ND & $64-128$ & $64-128$ & $64-128$ & ND \\
\hline Vancomycin & $1-2$ & $1-2$ & ND & $1-2$ & $2-8(16)$ & $4-16$ & ND & $4-16(32)$ \\
\hline
\end{tabular}

to cells exposed to VANC, they exhibited the same MIC values as the cells recovered from the control surfaces. $\mathrm{MBC}$ determination suggested the presence of heteroresistant or tolerant subpopulations, as some colonies could grow for some of the highest concentrations of vancomycin tested (denoted in brackets in Table 3). This phenomenon was observed on cells in contact with vancomycin but also on cells from the control surfaces (PDMS), so it cannot be merely attributed to the continuous pressure exerted by the immobilized antibiotic. Since a clinical isolate was used, the probability of being a heteroresistant or tolerant strain is higher [37].

\subsection{Susceptibility of cells adhered to modified surfaces to vancomycin chemotherapy}

To evaluate the susceptibility of cells adhered on MIX, these were subjected to vancomycin treatment overnight. Fig. 3 shows that, in the absence of treatment, the cells that managed to adhere to both unmodified and modified surfaces could grow exhibiting a higher metabolic activity. Vancomycin treatment had no effect on cells metabolic activity when these were allowed to adhere to unmodified PDMS or pDA. On the other hand, cells found adhered to MIX were more susceptible to antibiotic treatment, as evidenced by the decrease on their metabolic activity, suggesting a synergistic effect between modified surfaces and antibiotic therapy.

\subsection{Macrophages phagocytosis of adhered cells}

Phagocytosis of staphylococci by macrophages on unmodified modified surfaces was evaluated by an indirect method based on a previously reported method [21]. After allowing bacterial adhesion for $4 \mathrm{~h}$ to the different surfaces (Fig. $4 \mathrm{~A}-\mathrm{C}$ ), it was possible to observe that the number of adhered bacteria to functionalized surface MIX was lower than on control surfaces, corroborating previous findings [23]. After $2 \mathrm{~h}$ exposure to RPMI media without

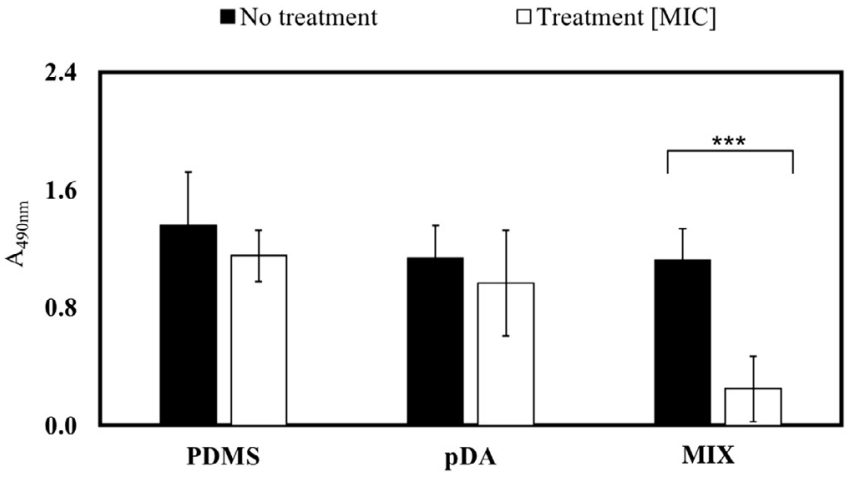

Fig. 3. Metabolic activity of cells of $S$. aureus GB $2 / 1$ adhered to unmodified PDMS, pDA-coated PDMS (pDA) and pDA-coated PDMS surfaces functionalized with DNase I and Palm (MIX), after being subjected to no treatment (black) or vancomycin treatment at its MIC (white). Significant differences were found for MIX (***) $\mathrm{p}<0.001$, compared to No treatment. macrophages, the fraction of adhered bacteria to PDMS slightly increased (Fig. 4D) whereas some detachment was observed for bacteria adhered to pDA-coated surfaces (Fig. 4E) which may be attributed to the hydrophilic features characteristic of this surface [38]. Cells adhered to MIX surface were not detached when exposed to solely RPMI (Fig. 4F). After macrophages contact with adhered staphylococci (Fig. 4G-I), significant reductions were found for all the surfaces, as compared to control RPMI, which is an indirect indication of bacterial phagocytosis [21]. These observations were confirmed by using ImageJ software to evaluate the attachment of staphylococci for all the conditions tested (see Fig. S3 of Supplementary Material). Results also showed that macrophages adhesion to unmodified PDMS tend to cluster while after pDA coating these cells were found more evenly distributed along the surfaces.

\section{Discussion}

In the fight against BAI, several surface modifications have been proposed to render the biomaterial surfaces with anti-infective properties [39]. Despite the promising results reported in the literature, where reductions on bacterial attachment higher than $90 \%$ are often achieved [17], most of these approaches tend to disregard the fate of the few bacteria that manage to attach to these modified surfaces. In our previous work, the co-immobilization of DNase I and Palm onto PDMS yielded a promising coating strategy with excellent anti-adhesive and antimicrobial properties without cytotoxicity [23]. However, it could not be neglected the fact that some bacteria managed to adhere to these coatings.

Bacteria have a striking ability to adapt in response to their environment, and in fact, some bacterial strains are not susceptible to some AMP in solution, even at high concentrations $[40,41]$. Results with planktonic cultures continuously exposed to a subinhibitory concentration of Palm also suggested some resistance towards the AMP in solution, evidenced by the 2-fold increase in MIC and MBC. In theory, compounds immobilization, without leaching, should decrease its propensity to induce bacterial resistance as there is no exposure to sub-inhibitory concentrations [19]. In fact, results found in this study suggested that both compounds immobilized on the surfaces (Palm and Vancomycin) exhibited a low propensity to develop bacterial resistance after a long period of exposure, 30 days.

Cell wall thickening is one of the molecular mechanisms of strains resistant to antimicrobials targeting the cell wall, such as vancomycin and antimicrobial peptides [42]. Therefore, three genes involved in this mechanism were first investigated. The two-component regulator system VraSR is known to upregulate the expression of enzymes involved in the peptidoglycan synthesis pathway [43] while the WalKR system plays a role in the regulation of cell wall metabolism-associated genes, specifically as a regulator of peptidoglycan biosynthesis during cross bridge hydrolysis [44]. Overexpression of vraSR activates the expression of a cluster of genes called the "cell-wall stimulon", which positively regulate synthesis of the cell wall, causing its thickening, thus increasing the resistance towards antimicrobials targeting the cell wall [43]. 


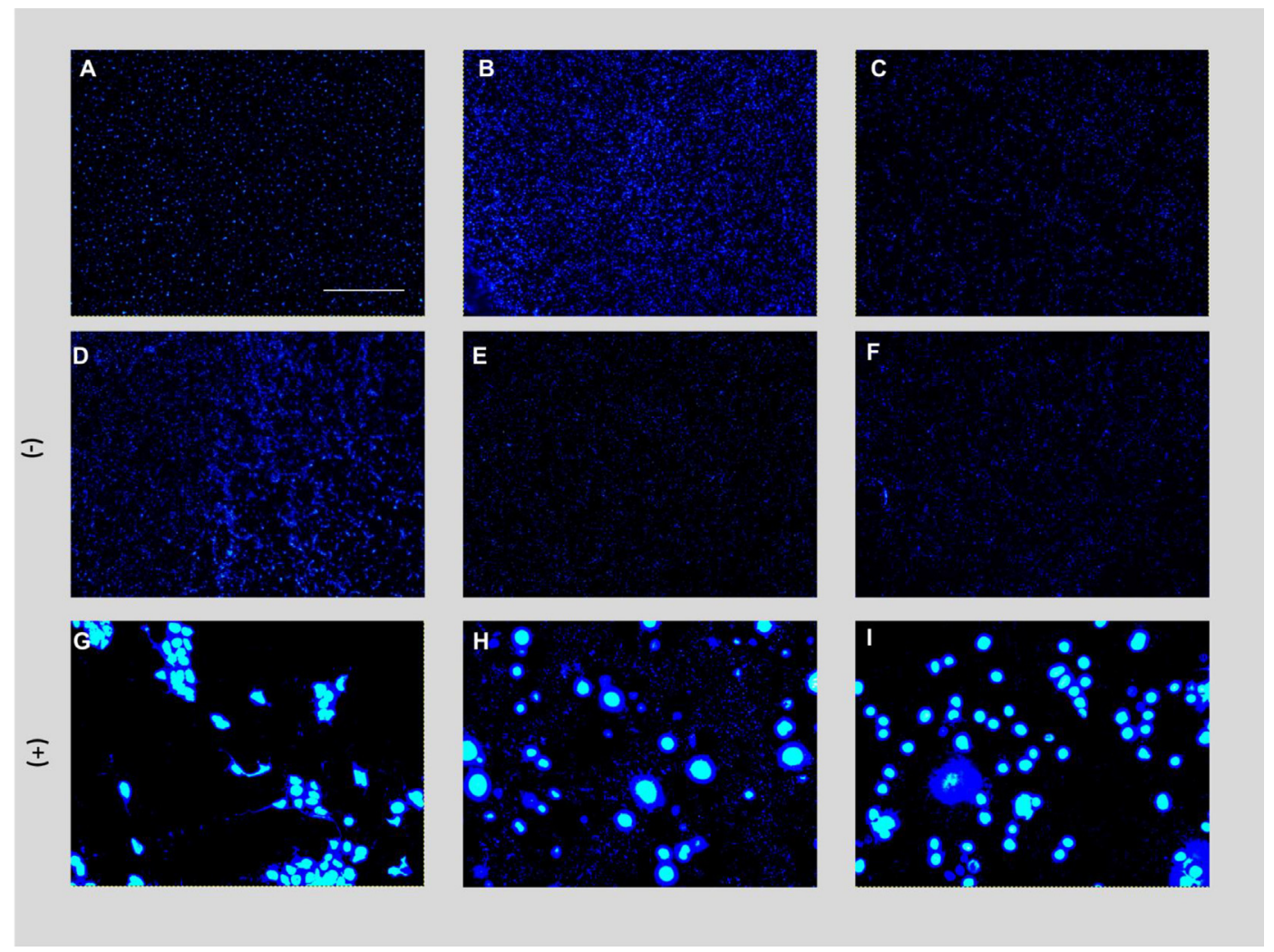

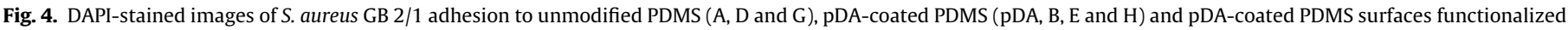

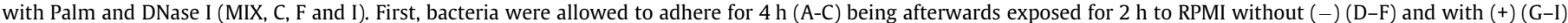
macrophages. The scale bar denotes $100 \mu \mathrm{m}$.

In a similar way, walKR overexpression has shown to result in increased resistance to vancomycin, probably through regulation of cell wall metabolism [44,45]. The gene encoding DNAdependent RNA polymerase $\beta$-subunit $(r p o B)$ is also commonly associated with increased resistance to vancomycin and increase cell wall thickness $[46,47]$. The expression levels of genes walKR and $v$ raSR were upregulated in the cells recovered from the control surfaces (PDMS and pDA), from the beginning until the end of the assay. Such profiles should be expected as the cells recovered from these surfaces had the necessary conditions to form biofilms, which have distinct patterns of gene expression as compared to their planktonic counterparts [36]. On the other hand, no differences were found on the expression level of $r p o B$ cells recovered from the control surfaces as compared to planktonic cultures, but a similar expression was observed for the cells exposed to the immobilized compounds.

Another mechanism used by bacteria to resist antimicrobials includes the upregulation of multi-drug resistant efflux pumps that include these compounds within their substrate profiles being responsible for their efflux from the cells [48]. Although the antimicrobials immobilized on the surfaces cannot be extruded by these pumps, it is important to investigate the expression of genes encoding these pumps to better understand the susceptibility of the cells adhered onto antimicrobial surfaces to a potential antimicrobial treatment. Continuous exposure to the functionalized surfaces altered the expression of norA gene, namely causing its downregulation while no difference was observed on expression profiles of $m d e A$ as compared to control surfaces.

Finally, the expression profile of known virulence related genes, namely $c l p P$ and hla, was also addressed. Alpha-hemolysin, also called alpha toxin, encoded by hla gene, is a protein which insertion into host cell membranes results in their lysis [49]. The prote- olytic subunit of the ATP-dependent Clp protease (ClpP) is encoded by $\mathrm{ClpP}$ gene. ClpP complexes are responsible for adaptation to several stress conditions by degrading accumulated and misfolded proteins, playing a crucial role in the survival and virulence of pathogens such as $S$. aureus [50,51]. A downregulation of the expression of hla gene was found for the cells recovered from the functionalized surfaces while no difference was found on the expression profiles of $c l p P$ as compared to control surfaces.

Overall, the expression analysis did not point out any development of resistance, since cells in contact with modified surfaces exhibited some genes involved in microbial resistance equally or less expressed, as compared to the ones recovered from control surfaces. The susceptibility patterns found for these cells also corroborated these findings.

Once a BAI is established, the most common approach of treatment involves the use of antibiotics, which dose must be higher than their MIC to be able to affect cells in sessile style [52]. Accordingly, in the present study, cells adhered to unmodified PDMS and pDA were not influenced by vancomycin treatment at its MIC. In the absence of treatment, cells adhered to modified surfaces exhibited a similar metabolic activity as those found on unmodified surfaces. These results suggest that bi-functional coatings alone may not be sufficient to effectively prevent BAI, when a complex and rich media such as TSB is used. When combined with vancomycin treatment, however, even using a lower concentration, S. aureus metabolic activity was significantly impaired on MIX. These results point out that antibiotic treatment of BAI could be more effective when these infections occurs after the implantation of a biomaterial holding this functional coating [53]. Enhanced bacterial susceptibility to antibiotic therapy may be attributed to the antimicrobial activity conferred by Palm immobilization. A similar mechanism of antimicrobial activity for immobilized quaternary 
ammonium compounds (QAC) on a substratum and positively charged surfaces, in general, has been proposed [54]. The authors showed that immobilized QAC-molecules enhanced the adhesion forces between bacteria and a surface to a lethally strong attraction, causing reduced growth, stress-induced deactivation and eventually leading to cell death. Since most of bacterial strains and species exhibit a negative surface charge [55], it is believed that strong adhesion forces can also be found on surfaces functionalized with cationic AMP that has proved to kill bacteria upon contact, in a so called "lethal" regime of strong adhesion forces [53]. Another factor that may have contributed to this higher susceptibility is associated to norA downregulation found for cells exposed to functionalized surfaces (VAN and MIX), which was kept over time. Although the expression of norA has been mainly associated with increased tolerance and efflux of a wide variety of structurally unrelated compounds (hydrophilic fluoroquinolones, benzalkonium, ethidium bromide and rhodamine) that does not include vancomycin, [48] the expression of the Nor-family efflux pumps is not fully understood and is likely influenced by several of host and environmental conditions [56,57]. Indeed, Kong et al. have reported that $S$. aureus tolerance to vancomycin treatment was attributed to upregulation of this drug efflux pump [57].

Upon the implantation of a biomaterial, tissue trauma and injury trigger a cascade of physiological events that activate the immune system [58]. The interactions between macrophages and bacterially contaminated biomaterials is, therefore, crucial for the establishment of a BAI. Indeed, mature biofilms are less likely to form if macrophages can remove and destroy bacteria adhering on a biomaterial surface. For further evaluation of the clinical potential of our bi-functional coating previously proposed [23] the in vitro response of human macrophages to $S$. aureus adhering to these coatings was also investigated and compared to unmodified surfaces. Results showed that macrophages were better distributed along pDA surfaces which suggests a better mobility to perform their phagocytic activity. In a previous study, on the interaction between macrophages and colonizing $S$. epidermidis, it was shown that macrophage behavior is surface dependent and macrophages on cross-linked PEG-based coatings exhibited enhanced cell motility compared to the motility on silicone rubber and glass [59]. Comparison of bacterial attachment on surfaces exposed to macrophages and RPMI media alone revealed a higher reduction on bacterial adhered to the surfaces in the presence of macrophages, an indirect indication of bacterial phagocytosis [21]. Results highlight that functionalization of PDMS with Palm and DNase I should not compromise the action of host immune cells which is a desirable feature for any coating strategy since some previous studies have demonstrated that immune cells may lose their ability to kill bacteria in the presence of a biomaterial $[60,61]$.

\section{Conclusions}

In conclusion, the small fraction of bacteria found adhered onto our antibacterial surfaces previously proposed [23] did not develop resistance towards the compounds immobilized, being even more susceptible to vancomycin chemotherapy. Modified surfaces did not compromise the action of host immune cells. Overall results added value to this antimicrobial coating strategy, as a good candidate for in vivo assays and its ultimate clinical application.

\section{Acknowledgements}

This study was supported by the Portuguese Foundation for Science and Technology (FCT) under the scope of the strategic funding of UID/BIO/04469/2013 unit and COMPETE 2020 (POCI01-0145-FEDER-006684) and BioTecNorte operation (NORTE-01-
0145-FEDER-000004) funded by the European Regional Development Fund under the scope of Norte2020 - Programa Operacional Regional do Norte. The authors also acknowledge the support by FCT and the European Community fund FEDER, through Program COMPETE, under the scope of the Project AntiPep PTDC/SAUSAP/113196/2009 (FCOMP-01-0124-FEDER-016012) and the PhD Grant of Diana Alves (SFRH/BD/78063/2011) and Andreia Magalhães (SFRH/BD/132165/2017). A special thanks to Doctor Agostinho Carvalho and Doctor Cristina Amorim from Life and Health Sciences Research Institute (ICVS), University of Minho for kindly providing the monocyte cell line used in this study. Doctor Nuno Cerca, from CEB, Centre of Biological Engineering, University of Minho, is also acknowledged for his important contribution on the interpretation of gene expression results.

\section{References}

[1] A. Larena-Avellaneda, G. Dittmann, C. Haacke, F. Graunke, R. Siegel, U.A. Dietz, E.S. Debus, Silicone-based vascular prosthesis: assessment of the mechanical properties, Ann. Vasc. Surg. 22 (2008) 106-114, https://doi.org/10.1016/j. avsg.2007.09.003.

[2] R. Bayston, L.E. Fisher, K. Weber, An antimicrobial modified silicone peritoneal catheter with activity against both Gram positive and Gram negative bacteria, Biomaterials $\quad 30 \quad$ (2009) 3167-3173, https://doi.org/10.1016/j. biomaterials.2009.02.028.

[3] A. Ernst, A. Majid, D. Feller-Kopman, J. Guerrero, P. Boiselle, S.H. Loring, C. O’Donnell, M. DeCamp, F.J.F. Herth, S. Gangadharan, S. Ashiku, airway stabilization with silicone stents for treating adult tracheobronchomalacia, Chest 132 (2007) 609-616, https://doi.org/10.1378/chest.06-2708.

[4] P.H.J. Keizers, M.J. Vredenbregt, F. Bakker, D. de Kaste, B.J. Venhuis, Chemical fingerprinting of silicone-based breast implants, J. Pharm. Biomed. Anal. 102 (2015) 340-345, https://doi.org/10.1016/j.jpba.2014.09.008.

[5] L. Rodrigues, I.M. Banat, J. Teixeira, R. Oliveira, Strategies for the prevention of microbial biofilm formation on silicone rubber voice prostheses, J. Biomed. Mater. Res. Part B Appl. Biomater. 81B (2007) 358-370, https://doi.org/ 10.1002/jbm.b.30673.

[6] L. Hall-Stoodley, J.W. Costerton, P. Stoodley, Bacterial biofilms: from the natural environment to infectious diseases, Nat. Rev. Microbiol. 2 (2004) 95108, https://doi.org/10.1038/nrmicro821.

[7] H.-C. Flemming, J. Wingender, The biofilm matrix, Nat. Rev. Microbiol. 8 (2010) 623-633, https://doi.org/10.1038/nrmicro2415.

[8] A.F. Engelsman, I.C. Saldarriaga-Fernandez, M.R. Nejadnik, G.M. van Dam, K.P. Francis, R.J. Ploeg, H.J. Busscher, H.C. van der Mei, The risk of biomaterialassociated infection after revision surgery due to an experimental primary implant infection, Biofouling 26 (2010) 761-767, https://doi.org/10.1080/ 08927014.2010 .515027

[9] I. Raad, J.A. Mohamed, R.A. Reitzel, Y. Jiang, S. Raad, M. Al Shuaibi, A.-M Chaftari, R.Y. Hachem, Improved antibiotic-impregnated catheters with extended-spectrum activity against resistant bacteria and fungi, Antimicrob. Agents Chemother. 56 (2012) 935-941, https://doi.org/10.1128/AAC.0583611.

[10] T.A. Gaonkar, L. Caraos, S. Modak, Efficacy of a silicone urinary catheter impregnated with chlorhexidine and triclosan against colonization with proteus mirabilis and other uropathogens, Infect. Control Hosp. Epidemiol. 28 (2007) 596-598, https://doi.org/10.1086/513449.

[11] J. Stensballe, M. Tvede, D. Looms, F.K. Lippert, B. Dahl, E. Tønnesen, L.S Rasmussen, Infection risk with nitrofurazone-impregnated urinary catheters in trauma patients: a randomized trial, Ann. Intern. Med. 147 (2007) 285-293 (accessed April 19, 2017) http://www.ncbi.nlm.nih.gov/pubmed/17785483.

[12] R.E. Gilbert, M. Harden, Effectiveness of impregnated central venous catheters for catheter related blood stream infection: a systematic review, Curr. Opin. Infect. Dis. 21 (2008) 235-245, https://doi.org/10.1097/ OCO.0b013e3282ffd6e0.

[13] D. Roe, B. Karandikar, N. Bonn-Savage, B. Gibbins, J.-B. Roullet, Antimicrobial surface functionalization of plastic catheters by silver nanoparticles, J. Antimicrob. Chemother. 61 (2008) 869-876, https://doi.org/10.1093/jac dkn034.

[14] D. Alves, M. Olívia, Pereira, Mini-review: Antimicrobial peptides and enzymes as promising candidates to functionalize biomaterial surfaces, Biofouling 30 (2014) 483-499, https://doi.org/10.1080/08927014.2014.889120.

[15] B. Gottenbos, H.C. van der Mei, F. Klatter, P. Nieuwenhuis, H.J. Busscher, In vitro and in vivo antimicrobial activity of covalently coupled quaternary ammonium silane coatings on silicone rubber, Biomaterials 23 (2002) 14171423 (accessed 19.04.17) http://www.ncbi.nlm.nih.gov/pubmed/11829437.

[16] X. Li, P. Li, R. Saravanan, A. Basu, B. Mishra, S.H. Lim, X. Su, P.A. Tambyah, S.S.J. Leong. Antimicrobial functionalization of silicone surfaces with engineered short peptides having broad spectrum antimicrobial and salt-resistant properties, Acta Biomater. 10 (2014) 258-266, https://doi.org/10.1016/j. actbio.2013.09.009. 
[17] M.R. Nejadnik, H.C. van der Mei, W. Norde, H.J. Busscher, Bacterial adhesion and growth on a polymer brush-coating, Biomaterials 29 (2008) 4117-4121, https://doi.org/10.1016/j.biomaterials.2008.07.014.

[18] J.D. Green, T. Fulghum, M.A. Nordhaus, Immobilized antimicrobial agents : a critical perspective, Science (80-) (2011) 84-98.

[19] J. Bruenke, I. Roschke, S. Agarwal, T. Riemann, A. Greiner, Quantitative comparison of the antimicrobial efficiency of leaching versus nonleaching polymer materials, Macromol. Biosci. 16 (2016) 647-654, https://doi.org/ 10.1002/mabi.201500266.

[20] C.M. Rosenberger, B.B. Finlay, Phagocyte sabotage: disruption of macrophage signalling by bacterial pathogens, Nat. Rev. Mol. Cell Biol. 4 (2003) 385-396 https://doi.org/10.1038/nrm1104.

[21] J.F. da Silva Domingues, H.C. van der Mei, H.J. Busscher, T.G. van Kooten, Phagocytosis of bacteria adhering to a biomaterial surface in a surface thermodynamic perspective, PLoS One. 8 (2013) e70046, https://doi.org/ 10.1371/journal.pone.0070046.

[22] J.J. Boelens, J. Dankert, J.L. Murk, J.J. Weening, T. van der Poll, K.P. Dingemans, L. Koole, J.D. Laman, S.A.J. Zaat, Biomaterial-associated persistence of staphylococcus epidermidis in pericatheter macrophages, J. Infect. Dis. 181 (2000) 1337-1349, https://doi.org/10.1086/315369.

[23] D. Alves, A. Magalhães, D. Grzywacz, D. Neubauer, W. Kamysz, M.O. Pereira Co-immobilization of Palm and DNase I for the development of an effective anti-infective coating for catheter surfaces, Acta Biomater. 44 (2016) 313-322, https://doi.org/10.1016/j.actbio.2016.08.010.

[24] G.B. Fields, R.L. Noble, Solid phase peptide synthesis utilizing 9fluorenylmethoxycarbonyl amino acids, Int. J. Pept. Protein Res. 35 (1990) 161-214 (accessed April 19, 2017) http://www.ncbi.nlm.nih.gov/pubmed/ 2191922.

[25] CLSI, Methods for dilution antimicrobial susceptibility tests for bacteria that grow aerobically, 2003.

[26] R.A. Cooper, L. Jenkins, A.F.M. Henriques, R.S. Duggan, N.F. Burton, Absence of bacterial resistance to medical-grade manuka honey, Eur. J. Clin. Microbiol. Infect. Dis. 29 (2010) 1237-1241, https://doi.org/10.1007/s10096-010-0992-1.

[27] C. Sousa, A. França, N. Cerca, Assessing and reducing sources of gene expression variability in Staphylococcus epidermidis biofilms, Biotechniques 57 (2014), https://doi.org/10.2144/000114238.

[28] A. França, A.I. Freitas, A.F. Henriques, N. Cerca, Optimizing a qPCR gene expression quantification assay for S. epidermidis biofilms: a comparison between commercial kits and a customized protocol, PLoS One 7 (2012) https://doi.org/10.1371/journal.pone.0037480.

[29] L. Tavares, P.M. Alves, R.B. Ferreira, C.N. Santos, Comparison of different methods for DNA-free RNA isolation from SK-N-MC neuroblastoma, BMC Res. Notes 4 (2011) 3, https://doi.org/10.1186/1756-0500-4-3.

[30] S. Rozen, H. Skaletsky, Primer3 on the WWW for general users and for biologist programmers, Methods Mol. Biol. 132 (2000) 365-386.

[31] A. França, L.D. Melo, N. Cerca, Comparison of RNA extraction methods from biofilm samples of Staphylococcus epidermidis, BMC Res. Notes. 4 (2011) 572 574, https://doi.org/10.1186/1756-0500-4-572.

[32] I. Kavanagh, G. Jones, S.N. Nayab, Significance of controls and standard curves in PCR, PCR Troubl. Optim. Essent. Guid. (2011) 67-78.

[33] M.W. Pfaffl, A new mathematical model for relative quantification in real-time RT-PCR, Nucleic Acids Res. 29 (2001) e45, https://doi.org/10.1093/nar/29.9.e45.

[34] M.G. Stevens, S.C. Olsen, Comparative analysis of using MTT and XTT in colorimetric assays for quantitating bovine neutrophil bactericidal activity, J. Immunol. Methods 157 (1993) 225-231, https://doi.org/10.1016/0022-1759 (93)90091-K.

[35] N.W. Roehm, G.H. Rodgers, S.M. Hatfield, A.L. Glasebrook, An improved colorimetric assay for cell proliferation and viability utilizing the tetrazolium salt XTT, J. Immunol. Methods 142 (1991) 257-265, https://doi.org/10.1016/ 0022-1759(91)90114-U.

[36] A. Resch, R. Rosenstein, C. Nerz, F. Gotz, Differential gene expression profiling of staphylococcus aureus cultivated under biofilm and planktonic conditions, Appl. Environ. Microbiol. 71 (2005) 2663-2676, https://doi.org/10.1128/ AEM.71.5.2663-2676.2005.

[37] H.S. Fraimow, C. Tsigrelis, Antimicrobial resistance in the intensive care unit: mechanisms, epidemiology, and management of specific resistant pathogens, Crit. Care Clin. 27 (2011) 163-205, https://doi.org/10.1016/j.ccc.2010.11.002.

[38] H. Lee, S.M. Dellatore, W.M. Miller, P.B. Messersmith, mussel-inspired surface chemistry for multifunctional coatings (accessed 21.04.17)(accessed 21.04.17), Science. (80-) (2007) 318.

[39] D. Campoccia, L. Montanaro, C.R. Arciola, A review of the clinical implications of anti-infective biomaterials and infection-resistant surfaces, Biomaterials 34 (2013) 8018-8029, https://doi.org/10.1016/j.biomaterials.2013.07.048.

[40] Z. Yu, W. Qin, J. Lin, S. Fang, J. Qiu, Antibacterial mechanisms of polymyxin and bacterial resistance, Biomed Res. Int. 2015 (2015) 1-11, https://doi.org/ $10.1155 / 2015 / 679109$.
[41] M.R. Yeaman, Mechanisms of antimicrobial peptide action and resistance, Pharmacol. Rev. 55 (2003) 27-55, https://doi.org/10.1124/pr.55.1.2.

[42] S. Maria-Neto, K.C. de Almeida, M.L.R. Macedo, O.L. Franco, Understanding bacterial resistance to antimicrobial peptides: From the surface to deep inside, Biochim. Biophys. Acta Biomembr. 2015 (1848) 3078-3088, https://doi.org/ 10.1016/j.bbamem.2015.02.017.

[43] H. Chen, Z. Xiong, K. Liu, S. Li, R. Wang, X. Wang, Y. Zhang, H. Wang, Transcriptional profiling of the two-component regulatory system VraSR in Staphylococcus aureus with low-level vancomycin resistance, Int. J. Antimicrob. Agents 47 (2016) 362-367, https://doi.org/10.1016/j. ijantimicag.2016.02.003.

[44] G. Bogosian, E.V. Bourneuf, A matter of bacterial life and death, EMBO Rep. 2 (2001) 770-774, https://doi.org/10.1093/embo-reports/kve182.

[45] A. Jansen, M. Türck, C. Szekat, M. Nagel, I. Clever, G. Bierbaum, Role of insertion elements and yycFG in the development of decreased susceptibility to vancomycin in Staphylococcus aureus, Int. J. Med. Microbiol. 297 (2007) 205-215, https://doi.org/10.1016/j.ijmm.2007.02.002.

[46] W.A. McGuinness, N. Malachowa, F.R. DeLeo, Vancomycin resistance in Staphylococcus aureus, Yale J. Biol. Med. 90 (2017) 269-281.

[47] L. Cui, T. Isii, M. Fukuda, T. Ochiai, H.M. Neoh, I.L.B. Da Cunha Camargo, Y. Watanabe, M. Shoji, T. Hishinuma, K. Hiramatsu, An RpoB mutation confers dual heteroresistance to daptomycin and vancomycin in Staphylococcus aureus, Antimicrob. Agents Chemother. 54 (2010) 5222-5233, https://doi. org/10.1128/AAC.00437-10.

[48] S. Santos Costa, M. Viveiros, L. Amaral, I. Couto, Multidrug efflux pumps in Staphylococcus aureus: an Update, 7 (2013) 59-71.

[49] S. Monecke, E. Müller, J. Büchler, B. Stieber, R. Ehricht, Staphylococcus aureus in vitro secretion of alpha toxin (hla) correlates with the affiliation to clonal complexes, PLoS One 9 (2014), https://doi.org/10.1371/journal.pone.0100427 e100427.

[50] A. Michel, F. Agerer, C.R. Hauck, M. Herrmann, J. Ullrich, J. Hacker, K. Ohlsen, Global regulatory impact of ClpP protease of Staphylococcus aureus on regulons involved in virulence, oxidative stress response, autolysis, and DNA repair, J. Bacteriol. 188 (2006) 5783-5796, https://doi.org/10.1128/JB.0007406 .

[51] J. Zhang, F. Ye, L. Lan, H. Jiang, C. Luo, C.-G. Yang, Structural Switching of Staphylococcus aureus Clp Protease, 2011, doi:10.1074/jbc.M111.277848.

[52] H. Nikaido, Multidrug resistance in bacteria, Annu. Rev. Biochem. 78 (2009) 119-146, https://doi.org/10.1146/annurev.biochem.78.082907.145923.

[53] H.J. Busscher, H.C. Van Der Mei, How do bacteria know they are on a surface and regulate their response to an adhering state?, PLoS Pathog 8 (2012), https://doi.org/10.1371/journal.ppat.1002440 e1002440.

[54] L.A.T.W. Asri, M. Crismaru, S. Roest, Y. Chen, O. Ivashenko, P. Rudolf, J.C. Tiller, H.C. Van Der Mei, T.J.A. Loontjens, H.J. Busscher, A. Shape-adaptive, Antibacterial-coating of immobilized quaternary-ammonium compounds tethered on hyperbranched polyurea and its mechanism of action, Adv. Funct. Mater. 24 (2014) 346-355, https://doi.org/10.1002/adfm.201301686.

[55] B.A. Jucker, H. Harms, A.J. Zehnder, Adhesion of the positively charged bacterium Stenotrophomonas (Xanthomonas) maltophilia 70401 to glass and Teflon, J. Bacteriol. 178 (1996) 5472-5479, https://doi.org/10.1128/ JB.178.18.5472-5479.1996.

[56] X. Deng, F. Sun, Q. Ji, H. Liang, D. Missiakas, L. Lan, C. He, Expression of multidrug resistance efflux pump gene norA is iron responsive in Staphylococcus aureus, J. Bacteriol. 194 (2012) 1753-1762, https://doi.org/ 10.1128/JB.06582-11.

[57] E.F. Kong, C. Tsui, S. Kucharíková, P. Van Dijck, M.A. Jabra-Rizk, Modulation of Staphylococcus aureus response to antimicrobials by the Candida albicans quorum sensing molecule farnesol, Antimicrob. Agents Chemother. 61 (2017), https://doi.org/10.1128/AAC.01573-17.

[58] Z. Xia, J.T. Triffitt, A review on macrophage responses to biomaterials, Biomed. Mater. 1 (2006), https://doi.org/10.1088/1748-6041/1/1/R01.

[59] I.C. Saldarriaga Fernändez, J.F. da Silva Domingues, T.G. van Kooten, S. Metzger, D.W. Grainger, H.J. Busscher, H.C. van der Mei, Macrophage response to staphylococcal biofilms on crosslinked poly(ethylene) glycol polymer coatings and common biomaterials In vitro, Eur. Cells Mater. 21 (2011) 73-79. doi: vol021a06 [pii].

[60] S.S. Kaplan, R.P. Heine, R.L. Simmons, Defensins impair phagocytic killing by neutrophils in biomaterial-related infection defensins impair phagocytic killing by neutrophils in biomaterial-related, Infection 67 (1999) 1640-1645.

[61] I. Watanabe, M. Ichiki, A. Shiratsuchi, Y. Nakanishi, TLR2-mediated survival of staphylococcus aureus in macrophages: a novel bacterial strategy against host innate immunity, J. Immunol. 178 (2007) 4917-4925, https://doi.org/10.4049/ jimmunol.178.8.491. 